\title{
Implementation of cleaner production practices with the support of a diploma course
}

\author{
Asher Kiperstok * \\ Department of Hydraulics and Sanitation, Federal University of Bahia, Rua Aristides Novis 02, Federação, 40210-630, Salvador, Bahia, Brazil
}

\begin{abstract}
This paper describes the initial proposal of a cleaner technologies network in the state of Bahia, in the northeast section of Brazil. This network intends to bring together industry, universities, and government to discuss the relationship between production and the environment. Its main objective is to support a change in the way this relationship is nowadays perceived, in order to make preventive practices a priority and improve eco-efficiency. Implementation of the network was preceded by a diploma course on environmental technologies and management directed at professionals in the workforce. The results of the course are helping to create an atmosphere that is beneficial for the start-up of the network. (c) 2000 Elsevier Science Ltd. All rights reserved.
\end{abstract}

Keywords: Cleaner production; Networking; Clean technology; Training; Training for eco-efficiency

\section{Introduction}

If cleaner production practices so obviously make common sense, why should we take the time to develop programmes to expand and support them? Why do they not occur naturally in industry? Are they just an academic preoccupation?

These questions were raised during the birth of TECLIM, a programme conceived in 1997 by the Department of Hydraulics and Sanitation and the Department of Chemical Engineering at the Federal University of Bahia, Brazil, to promote cleaner practices in industry. Initial contacts with representatives from the chemical industry and industrial associations helped to clarify the issues.

At the outset of the programme, it became clear that none of the above questions have a single, simple yesor-no answer, and that addressing these questions would require taking several factors into account. First, outside environmental pressures have affected industry. The predominant focus inside the facility limits of plants on increasing production and profits now shares attention with growing societal concerns about protecting the environment. To address this tension, end-of-pipe meas-

\footnotetext{
* Tel.: +55-71-2354436.

E-mail address: asher@ufba.br (A. Kiperstok).
}

ures have flourished as the favored means of industry and governments for balancing interests.

Second, recent industrialisation in many developing countries has been encouraged by protective measures adopted by their governments to gain greater economic independence. These measures were designed to boost local enterprises and develop substitutes for imported goods, thereby generating jobs at a local level. To foster industrialisation in the 60's and 70's, governments and private national interests formed alliances to create opportunities to attract foreign investors and technology. Huge investments in infrastructure were made, and raw materials were subsidized. In Brazil, for example, this approach was termed the 'economical miracle' — yet generated an external debt and dependence that contributed to the country's economic stagnation of the 80's and 90 's. Under official protection, industry grew with few demands for efficiency as long as it was able to generate profits for shareholders. As a result of this development model, high rates of inflation became endemic in third world countries. Environmental constraints were initially relaxed and then subsequently enforced, but governments subsidised industry's compliance costs.

Third, in the 90's, globalisation forced industry to search for new patterns of production to survive under more competitive circumstances. Environmental constraints have grown more stringent, as standards have 
been exported from more developed and saturated markets to the less developed world. Countries that have already destroyed all their original ecosystems are putting pressure on those who still have some untouched areas to preserve them. This kind of global sense of guilt may change the present trend of biodiversity reduction.

The questions initially posed by TECLIM were gradually answered. To some professionals in industry, it was obvious that pollution should be addressed at the source in order to avoid unnecessary consumption of raw materials and the additional costs of destroying unspent inputs. Those who recognised the need for a change in behaviour saw TECLIM's initiative as an opportunity to find other people who thought the same way as they did. Nevertheless, the vast majority of their colleagues still reacted in an old-fashioned way by favoring pollution control. This response indicated that not all TECLIM participants perceived the new reality of the need for a prevention-based approach and that a change in established ways of thinking, not just individual attitudes, is required.

\section{TECLIM (Clean Technologies) programme}

The clean technology programme attempts to create a network linking industry, government, and universities to promote the use of clean technologies in local facilities. Institutions taking part in this programme include universities and technical schools, industrial associations, training and centres for technology, environmental agencies as well as industrial and consulting firms, and industrial water and wastewater treatment firms.

The programme is financially supported by the Brazilian Research Council, CNPq and the Research Co-operative Network - RECOPE - funded by the Federal Government and the State Government of Bahia [2].

The initial design for TECLIM included five workgroups, as indicated in Fig. 1. These workgroups address the following topics: 1) environmental management for the transfer of cleaner technologies, 2) information systems, 3) environmental optimisation of processes, 4) development of bio-indicators to assess the toxicity of industrial wastewater, and 5) education and training. These workgroups are meant as a starting basis for the development of future initiatives or co-operative projects [2].

The first workgroup seeks to study environmental management systems that are already in place in local firms (all large companies). The objectives of this study are to develop a methodology for the implementation of cleaner production practices in large, medium and small firms, with or without previous EMS experience, and to identify mechanisms to promote the integration between industrial sectors to allow the use of residues of one plant to be used as raw materials of another.
The information system workgroup seeks the implementation of an information framework to support the expansion of clean technologies. This framework attempts to facilitate the exchange of opinions and information between the network partners and the public at large. This system will provide the virtual space needed to allow the network partners to meet and carry out their activities. It will also support educational and training activities and a database offering technical information and summaries of successful experiences. The initial homepage can be found at http://www.teclim.ufba.br

The third workgroup is engaged in research into the environmental optimisation of processes. The research aims to develop and apply mathematical programming methods to support the identification of cleaner industrial configurations. The workgroup also seeks cooperation between industry and the university to carry out research into the reduction of industrial effluent toxicity.

The fourth workgroup, coordinated by UFBA's Institute of Biology, seeks to develop bio-indicators to assess the toxicity of industrial wastewater. By adapting biomonitoring methods to the reality of local industry, the workgroup intends to prioritise efforts for the segregation of industrial waste streams.

Finally, the education and training workgroup's objective is to insert a pollution prevention approach into engineering courses at UFBA and other local universities. At the moment, the main initiative being implemented is the Diploma Course in Environmental Management and Technologies in Industry. An effort is also being made to deliver this course using distance learning techniques. The workgroup is also attempting to make available recent information on pollution prevention and environmental technologies to professionals already positioned in the market place.

\section{The diploma course on environmental management and technologies in industry}

To initially spread the cleaner production concept among industry and government, the School of Engineering of the Federal University of Bahia and the Industrial Technology Centre (CETIND) of the National Industrial Training Service worked together to put forward a diploma course on environmental management and technologies. The idea was discussed in 1997 with professionals working in industry, and the first course was offered in March 1998 in the city of Salvador, Bahia's capital. Due to the success of this first course, a second course was offered in 1999.

The Diploma Course on Environmental Management and Technologies in Industry is a 550-hour course delivered in the evenings to encourage the participation of professionals working in industry. The eight-module course, which runs over the course of 12 months, 


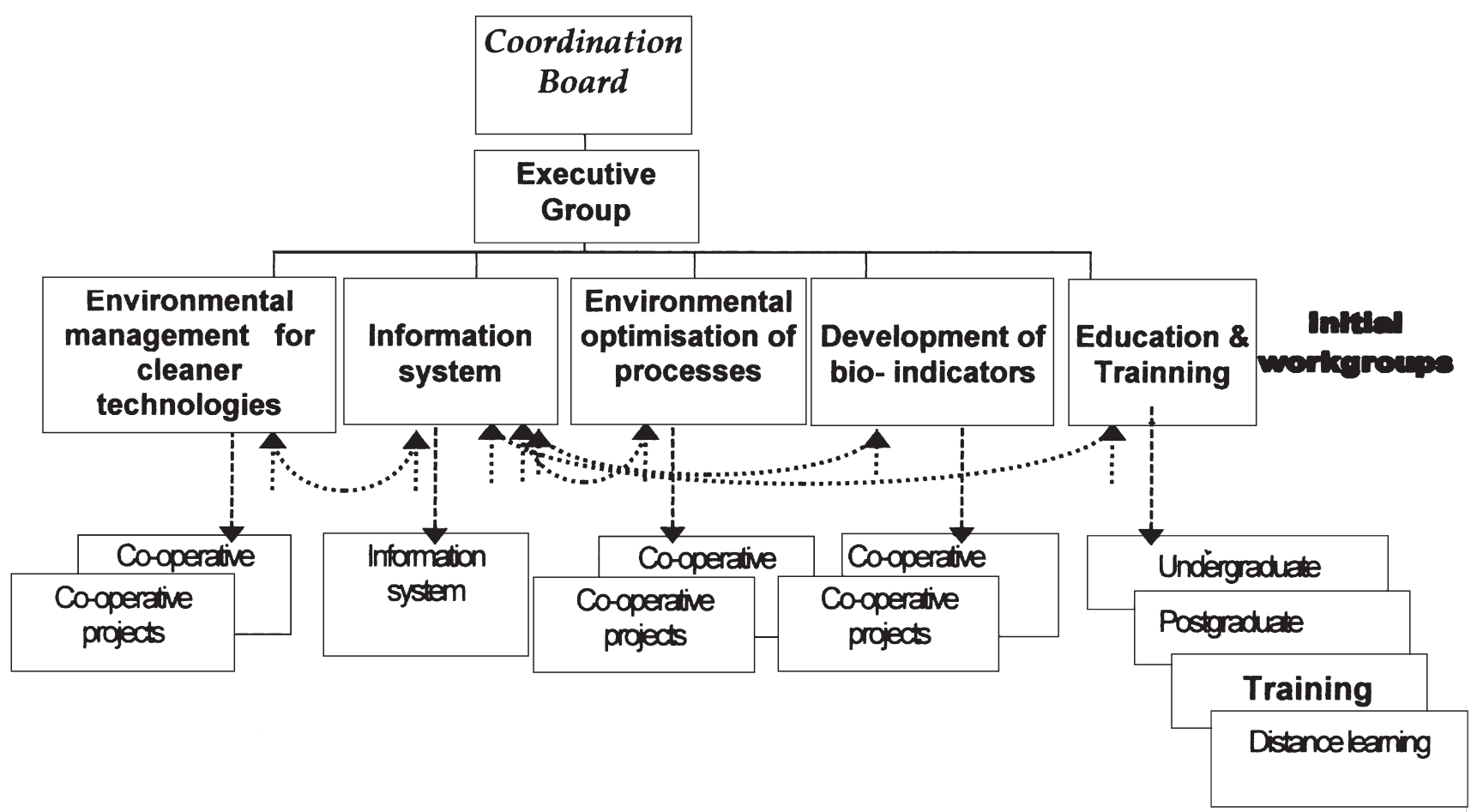

Fig. 1. Proposal for TECLIM's structure [2].

includes 340 class instruction hours and the writing of a small research project with an estimated duration of not less than 210 hours over six months. (see Table 1). The course begins with a review of environmental management issues. It then presents technological issues in a sequence that follows the order of priorities rec-

Table 1

Course modules and subjects [1]

\begin{tabular}{lc}
\hline Modules and subjects & Hours \\
\hline I — Environmental management & 60 \\
Ia - Economics and environment & 15 \\
Ib - Legal and institutional aspects & 15 \\
Ic - Environmental impact assessment & 15 \\
Id - Environmental management systems & 15 \\
II - Introduction to research methods & 18 \\
III - Environmental technologies & 126 \\
IIIa - Clean technologies and waste minimisation & 36 \\
IIIb - Liquid effluents & 27 \\
IIIc - Atmospheric emissions & 15 \\
IIId - Solid wastes & 21 \\
IIIe - Remediation of contaminated soils & 27 \\
IV - Behaviour of pollutants in the environment & 60 \\
IVa - Toxicology & 15 \\
IVb - Physical and chemical aspects & 21 \\
IVc - Biological aspects & 24 \\
V - Risk analysis and safety & 30 \\
VI - Case studies & 16 \\
VII - Supervised research work & 210 \\
VIII - Workshop for the presentation of best research & 30 \\
works and discussion of future scenarios & 550 \\
Total & \\
\hline
\end{tabular}

ommended to deal with environmental practices in industry, namely, first solving problems at the source. If managerial or technological competence is not available, or is insufficient to prevent all possible pollution at the source, end of pipe abatement and disposal techniques have to be considered. The course reviews the pollution prevention hierarchy for discharges to water, air and land.

In addressing the behaviour of pollutants in the environment, course instructors encourage debate over toxicological issues as well as the principles that govern the transference and transformation of pollutants in physical and biological structures. In reviewing risk and safety issues, the course intends to give participants basic information to allow them to participate in working groups bringing together environmental and safety matters.

Although practical examples are discussed throughout the course, a special section is dedicated to the presentation of successful case studies from small to large industrial firms. Students have contributed to the course by identifying and suggesting interesting cases to be presented and discussed. Some of these are international experiences presented by representatives of multinational firms, suggested and supported by participants of the course who themselves work for their Brazilian branches.

The inclusion into the curriculum of the experiences of small firms is of special interest. The course, as part of the TECLIM programme, aims to reach not just large 
Table 2

Students' profile $[1,3]$

\begin{tabular}{|c|c|c|c|c|c|c|c|c|}
\hline By working place & 98 & 99 & By profession & 98 & 99 & By experience & 98 & 99 \\
\hline Large size, chemical industry & 15 & 20 & Chemical engineer/Chemist & 15 & 17 & $\begin{array}{l}\text { Medium in environmental issues, } \\
\text { large in related areas }\end{array}$ & 17 & 22 \\
\hline Consulting firm & 9 & 9 & Manager/Economist & 3 & 1 & Little & 13 & 6 \\
\hline University & 6 & - & Biologist & 4 & - & Large in environmental issues & 8 & 6 \\
\hline Environmental agency & 3 & 1 & Mechanical engineer & 4 & 4 & & & \\
\hline Computing firms & 2 & - & Safety engineer & 4 & 5 & & & \\
\hline Industry federation & 2 & 1 & System analyst & 2 & - & & & \\
\hline Medium size industry & 1 & 1 & Geologist & 2 & 2 & & & \\
\hline \multirow[t]{4}{*}{ Research centre } & - & 2 & Metallurgical engineer & 2 & - & & & \\
\hline & & & Architect & 1 & - & & & \\
\hline & & & Civil engineer & - & 2 & & & \\
\hline & & & Other & 1 & 3 & & & \\
\hline Total & 38 & 34 & & 38 & 34 & & 38 & 34 \\
\hline
\end{tabular}

and medium firms, but also small firms with very little technological know-how. One way to achieve this goal is to bring together professionals working in large firms, who have access to more current technologies, with colleagues who understand the realities of working in smaller firms. Students are also encouraged to choose small firms as the subject of their research work.

\section{Experiences with the diploma course}

In 1998, 38 students participated in the first offering of the course, and in 1999, the course enrolled 34 students. A profile of the students reflects a variety of professions, levels of experience, and places of employment (Table 2) [1,3]. Contributing lecturers are recruited both from university and industry to facilitate the association between academic and more applied thinking. A profile of the lecturers is presented in Table $3[1,3]$.

Interdisciplinary work is promoted in and out of class to facilitate a broader comprehension of environmental problems. This approach reproduces the kind of real-life interaction that must be dealt with positively in industry. At the same time, it also poses a challenge to the lecturers who, because they are facing an audience with a broader industrial experience than their own, tend to draw upon the students' own experiences and diverse educational and professional backgrounds. The participants' diverse backgrounds and interests, combined with the lecturers' experiences and desire to develop an interdisciplinary process of teaching and learning, have fostered a discussion environment where practical views confront theoretical frameworks. At times, lecturers are compelled to assume the role of mediators in an ongoing debate.

The course has also demonstrated that encounters between individuals with specialised knowledge and those with different, broader experiences may facilitate the discovery and implementation of cleaner production practices. Students in the course with more expertise in a specific subject tended to help less experienced colleagues, and differences in skill levels contributed to the generation of new approaches to the problems being discussed. These interactions enriched not only the students' knowledge but also the lecturers' [4,5]. If reproduced on a larger scale, this phenomenon could contribute to the introduction of cleaner practices in industry. It could also be replicated in other university classrooms.

Initially conceived just as one of the activities supporting TECLIM, the diploma course has shown great potential to support the development of the TECLIM programme as a whole, as well as develop as a longterm activity in its own right. This potential has emerged from the intense exchange of opinions occurring in class and could constitute a strong movement towards cleaner production if expanded through the information system and distance learning methods being developed by the

Table 3

Lecturers' profile [1,3]

\begin{tabular}{lrllrr}
\hline Institution & 98 & 99 & Highest qualification & 98 & 99 \\
\hline University & 13 & 15 & $\mathrm{PhD}$ & 11 & 13 \\
Industry/Consulting/Government & 8 & 13 & $\mathrm{MSc}$ & 6 & 9 \\
Total & 21 & 28 & Diploma & 4 & 6 \\
\hline
\end{tabular}


TECLIM programme [4,5]. The gradual transformation of the course into a distance learning course will allow the generation of information that may be used to feed the information system. Moreover, the success of the information system will promote the course. Course research work will be published and publicised through the programme's information system as well as other conventional means. The idea is to encourage other stakeholders to take part in the debate and bring their cleaner production experiences into the public space.

\section{Conclusion}

Our experience with the Diploma Course on Environmental Management and Technologies in Industry has shown that the course's educational approach contributes to the success of both the course itself and the broader industrial cleaner technologies programme (TECLIM) of which the course is a part. While TECLIM's information system enhances the course's impact by reaching more professionals as well as supporting the students' professional growth even after they complete the course, the debates and research projects generated in the course, in turn, feed the information system. Bringing the diploma course together with other TECLIM initiatives also fosters greater interaction between industry and academic institutions.
A multidisciplinary approach is advantageous to the implementation of courses similar to the diploma course. Benefits of such an approach include the enrichment of class debates, the fostering of multi-focused views, and the development of new ideas. Although maintaining a multidisciplinary approach requires instructors to rethink their lectures and present them in an entirely new way, the positive response from students may well be worth the effort.

\section{References}

[1] Kiperstok A, Cardoso LF. Teclim/UFBa, Relatório do Curso de Especialização em Gerenciamento e Tecnologias Ambientais na Indústria, elaborado para o PADCTIII. Salvador, Bahia: Capes, 1999.

[2] Kiperstok A, Pacheco Filho JG. Teclim/UFBa, Rede de Tecnologias Limpas e Minimização de Resíduos na Indústria, proposta apresentada ao edital Recope. Salvador, Bahia: Cadct/Finep, 1998.

[3] Kiperstok A. Teclim/UFBa, Relatório do Primeiro Curso de Especialização em Gerenciamento e Tecnologias Ambientais na Indústria. Bahia: Salvador, 1998.

[4] Kiperstok A. Tecnologias Limpas, Capacitação e Pesquisa. Tecbahia 1998;13(1):136-9.

[5] Kiperstok A. Implantação de uma rede de cooperação em tecnologias limpas como o apoio de cursos de especialização. O curso de especialização em gerenciamento e tecnologias ambientais na industria da UFBA. Anais do II simposio intenacional de qualidade ambiental, Porto Alegre, Outubro, 1998:564-570. 